\title{
Kinetics of silica precipitation in geothermal brine with seeds addition: minimizing silica scaling in a cold re-injection system
}

\author{
Felix Arie Setiawan', Edia Rahayuningsih², Himawan Tri Bayu Murti Petrus ${ }^{2,3}$, Muhammad Istiawan Nurpratama $^{4}$ \\ and Indra Perdana ${ }^{2,3^{*}}$ (D)
}

*Correspondence:
iperdana@ugm.ac.id
${ }^{2}$ Dept. of Chemical
Engineering, Faculty
of Engineering, Universitas
Gadjah Mada, Jl.
Grafika 2 Bulaksumur,
Yogyakarta 55281, Indonesia
Full list of author information
is available at the end of the
article

*Correspondence: iperdana@ugm.ac.id Engineering, Faculty of Engineering, Universitas Gadjah Mada, J. Grafika 2 Bulaksumur, Full list of author information article

\begin{abstract}
The utilization of geothermal energy remains underdeveloped, mainly due to the technical problem of silica scaling. The scaling can eventually disrupt the electricity production process due to frequent pipe maintenance. Although inevitable, scaling can be controlled by accelerating the precipitation process through the addition of silica seeds. Silica gel has an affinity to bind with dissolved silica in geothermal brine that therefore reduces the likelihood of silica to form scale on the pipeline surfaces. In the present work, brine was taken from geothermal well Unit 3A-3B at the Dieng geothermal power plant with an initial silica monomer concentration of approximately $420 \mathrm{ppm}$. Silica gel seeds were added to the brine at a precise $\mathrm{pH}$ and temperature and dissolved silica concentration was analyzed by detecting silica monomers with UV-visible spectrophotometry using the vanadate/molybdate (yellow) method. Experimental results showed that the silica concentration in the liquid phase could be reduced by the addition of these seeds. Silica precipitation was determined by mass transfer of silica monomers from the fluid phase onto solid surfaces, and it was found that precipitation decreased as $\mathrm{pH}$ and temperature increased. Calculations also showed that the mass transfer coefficient was enhanced by fluid agitation. The silica precipitation process was optimal at a pH of 7, a temperature of $40^{\circ} \mathrm{C}$ and agitation speed of $800 \mathrm{rpm}$; the result was a mass transfer coefficient of $0.5924 \mathrm{~cm} / \mathrm{s}$. In a dimensionless correlation, the mass transfer coefficient can be expressed in the equation $\left(k_{c} \cdot d_{\mathrm{p}} / D_{\mathrm{AB}}\right)=1.4242 \cdot R e^{0}$. ${ }^{529} \cdot \mathrm{SC}^{0.3333}$.
\end{abstract}

Keywords: Geothermal, Seeding, Silica precipitation, Scaling mitigation, Mass transfer

\section{Introduction}

Depletion of fossil fuels has driven efforts to find other sources of renewable energy. Located in the Ring of Fire, Indonesia has approximately $28.91 \mathrm{GW}$ of geothermal energy potential, but less than $5 \%$ of these resources have been utilized thus far (Pambudi 2018). The Indonesian government plans to improve the utilization of geothermal power plants; unfortunately, as demonstrated in Fig. 1, it can be seen that electricity generation from geothermal power plants in Indonesia has thus far increased only incrementally. The utilization of energy generation is dependent upon the quality of the geothermal fluid; such fluid is not always suitable for existing

(c) The Author(s) 2019. This article is distributed under the terms of the Creative Commons Attribution 4.0 International License (http://creativecommons.org/licenses/by/4.0/), which permits unrestricted use, distribution, and reproduction in any medium, provided you give appropriate credit to the original author(s) and the source, provide a link to the Creative Commons license, and indicate if changes were made. 


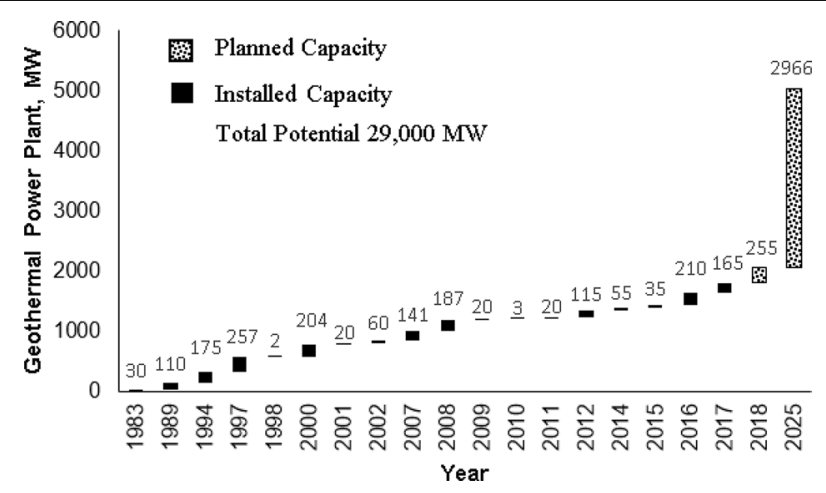

Fig. 1 Geothermal power plant generation in Indonesia: past, present and future

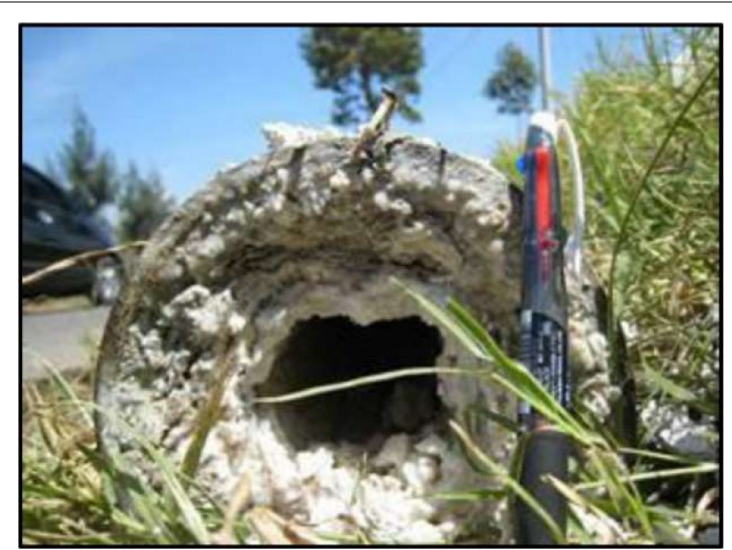

Fig. 2 Clogged pipe at Dieng Geothermal Power Plant despite using acidification to prevent silica scaling (Pambudi et al. 2015)

technologies. In case of acidic geothermal fluid, the fluid may contain high concentration of dissolved minerals leading to the formation of scales as seen in Fig. 2 as occurred in Dieng's geothermal power plant which frequently causes disruption of electric generation. Silica scaling especially becomes a serious problem in a geothermal power plant which applies binary cycle system. In case of wet geothermal fluid, the brine from separator might contain high concentration of silica in an oversaturated condition (Haklidir and Balaban 2019). Without any intervention of scaling prevention, the silica in the brine tends to form scales on the surfaces of downstream equipment (Haklidir and Haklidir 2017).

Dissolved silica in the brine is in the form of silicic acid monomers. Due to temperature and $\mathrm{pH}$ changes, the monomeric silica may precipitate to form particles that eventually leads to formation of scales. In some cases, the scales cause disruption of brine circulation as a heat carrier. The formation of scales can also disturb brine re-injection process to the reservoir. The power plant generation even needs to stop its operation due to a severe scaling formation. The scale is commonly very difficult to remove and can damage equipment over prolonged period operation leading to an increase in overall operating costs of geothermal power plant (Durham and Walton 1999). 
A great deal of research has been conducted to address the silica scaling problem, with little success. Milne et al. (2014) compared several processes for overcoming silica deposition and discussed their advantages and disadvantages. The approach most often used to mitigate silica deposition utilizes the principle of silica solubility as a function of $\mathrm{pH}$, leading to the addition of acids at various points (Klein 1995). Okamoto et al. (2010) explored a continuous system using columns with packed quartz sand material as a separation medium for dissolved minerals, which yielded a decrease in Si concentration of $50 \mathrm{ppm}$ at a temperature below $350{ }^{\circ} \mathrm{C}$. To control silica precipitation, Kashpura and Potapov (2000) used coagulants to accelerate it, studying the rate of silica precipitation and calculating that the polymerization rate constant of silicic acid was about $0.485 / \mathrm{h}$ between 120 and $150{ }^{\circ} \mathrm{C}$. Jarvenin (2008) explained the difference between precipitation and crystallization which is more likely related to the rate of the process and the size of the resulting solid particles. The precipitation process can be divided into two paths according to Mersmann (2001) namely primary nucleation and secondary nucleation which is differentiated by the nuclei existence in the solution.

Sugita et al. (2000) introduced different kind of seeds, i.e., silica gel, geothermal colloidal silica and scale-originated seeds to control precipitation of silica in geothermal brines. They found that silica gel and colloidal silica can accelerate silica precipitation and decrease silica concentration in geothermal brine from 500 to $340 \mathrm{ppm}$. The seeds provided extensive surfaces for monomeric silica in the brine to precipitate. In their other works (Sugita et al. 1998, 2003), it was shown that the use of seeds can enhance precipitation rate. However, the works have not yet described the mechanism of precipitation including the particle growth on the seeds. Understanding the mechanisms of seed growth and their kinetics could greatly improve the mitigation of silica scaling in the geothermal power plant.

Another study confirmed that the precipitation process could be accelerated by the presence of seeds as found by Tai et al. (2005). The formation of nuclei occurs due to the reaction of silica monomers to form dimers. This reaction requires hydroxyl ions as a catalyst (Brown 2011). Introduction of seeds is a method to overcome induction phase and formation of nuclei whose duration is much longer compared to the time consumed for the growth. Addition of the seeds into the solution results in a higher concentration gap between monomers in the solution and the seeds that leads to higher rate of precipitation. The higher concentration difference at the boundary layer between the seed surface and the solution would increase driving reaction forces as specified by the convective mass transfer equation. This principle has also been used in sugar crystallization processes.

The present work investigated the effect of seed addition into geothermal brine on the precipitation process. A mathematical model was proposed to represent silica precipitation from liquid bulk onto solid surfaces of the seed, which would accommodate the unique distinctions between the geothermal wells worldwide. The study also outlined the dimensionless variable correlation to estimate mass transfer. The contributions of both the model and the generalization of the mass transfer coefficient serve to improve the efficiency of designing systems to mitigate silica precipitation (Zlokarnik 2006). 


\section{Materials and methods Materials}

Geothermal brine was collected from the geothermal well in Unit 3A-3B at Dieng's geothermal power plant, Central Java, Indonesia with composition presented at Table 1 . Whatman 41 filter paper was used to separate liquid and solid phases. Some chemicals which are silica standard solution $\left(\mathrm{SiCl}_{4}\right.$, analytical grade), silica gel with particle size of 70-230 mesh as silica seed (analytical grade), ammonium heptamolybdate $\left(\left(\mathrm{NH}_{4}\right)_{6} \mathrm{Mo}_{7} \mathrm{O}_{24} \cdot 4 \mathrm{H}_{2} \mathrm{O}\right.$, analytical grade), hydrochloric acid ( $\mathrm{HCl}$, analytical grade), and sodium hydroxide (chemical grade) were supplied by Merck, while sulfuric acid $\left(\mathrm{H}_{2} \mathrm{SO}_{4}\right.$, pro-analysis grade) was supplied by Panreac.

\section{Silica precipitation}

Two hundred $\mathrm{mL}$ of geothermal brine with a monomeric silica concentration of $6.96 \times 10^{-3} \mathrm{~mol} / \mathrm{L}$ was collected from the Dieng plant Unit 3A-3B, and hydrochloric acid was added to lower the $\mathrm{pH}$ to 2.5 to prevent precipitation of the silica. The brine was then poured into a $250-\mathrm{mL}$ beaker glass, placed on a hot magnetic stirrer plate, and up to 0.4 grams of silica gel seeds were added to the solution. Sodium hydroxide was added to adjust the $\mathrm{pH}$ to 7,8 or 9 , and the temperature was set at 25,40 or $80^{\circ} \mathrm{C}$ to investigate $\mathrm{pH}$ and temperature effects. To investigate the effect of turbulence on the precipitation, stirring speed was varied at 300,450 and $800 \mathrm{rpm}$ at a constant $\mathrm{pH}$ of 7 and temperature of $40^{\circ} \mathrm{C}$.

\section{Analysis of monomeric silica concentration}

Samples of $1 \mathrm{~mL}$ were taken during the precipitation process at $0,15,30,45,60$ and $90 \mathrm{~min}$ and filtered through Whatman 41 filter paper at a pore size of 20 to $25 \mu \mathrm{m}$. The sample was diluted with distilled water to $20 \mathrm{~mL}$, and $0.205 \mathrm{~mL}$ ammonium heptamolybdate $100 \mathrm{~g} / \mathrm{L}$ was added along with $0.205 \mathrm{~mL} \mathrm{H}_{2} \mathrm{SO}_{4} 1.5 \mathrm{M}$. The solution was stirred for $5 \mathrm{~min}$ and then stabilized for $5 \mathrm{~min}$. The absorbance of the solution was measured using a Vernier SpectroVis Plus Spectrophotometer with Logger Pro ${ }^{\circledR} 3$ software at a wavelength of $400 \pm 10 \mathrm{~nm}$.

\section{Particle size analysis of solid particles}

Particle size distribution of the initial silica seeds was measured using an LA-950 laser-scattering particle size distribution analyzer (Horiba Ltd.) with the method described by Petrus et al. (2011). Information from this measurement was used for modeling the mass transfer coefficient. The surface area of the seeds referred to silica gel properties was $510 \mathrm{~m}^{2} / \mathrm{kg}$. The size of precipitated particles was determined from images of scanning electron microscopy (SEM) that was also to describe precipitation phenomena.

\section{Data analysis}

The mass balance of monomeric silica concentration that experiences precipitation in the brine is calculated as shown in Eq. 1. As suggested by Sugita et al. (2003), total surface area per volume $(A)$ of silica seed insignificantly changes during precipitation because the amount of silica to precipitate is relatively small. Therefore, the value of $A$ can be assumed constant and equal to its initial surface area of $A_{\mathrm{o}}$.

$$
\frac{d\left(C_{\mathrm{A}} \cdot V\right)}{\mathrm{dt}}=-k_{\mathrm{c}} \cdot A \cdot\left(C_{\mathrm{A}}-C_{\mathrm{Ai}}\right) V
$$




$$
\frac{d C_{\mathrm{A}}}{\mathrm{d} t}=-k_{\mathrm{c}} \cdot A_{\mathrm{o}} \cdot\left(C_{\mathrm{A}}-C_{\mathrm{Ai}}\right)
$$

where $\frac{d C_{\mathrm{A}}}{\mathrm{d} t}$ is the rate of silica precipitation in $\mathrm{mol} / \mathrm{L} / \mathrm{s} ; k_{\mathrm{c}}$ is the mass transfer coefficient in $\mathrm{cm} / \mathrm{s} ; C_{\mathrm{A}}$ is the monomeric silica concentration within time in $\mathrm{mol} / \mathrm{L} ; C_{\mathrm{Ai}}$ is the preequilibrium monomeric silica concentration in $\mathrm{mol} / \mathrm{L} ; V$ is the total volume of solution in $\mathrm{L}$; and $A_{\mathrm{o}}$ is the surface area of initial seed in $\mathrm{cm}^{2}$.

The amount of precipitated silica can then be calculated by developing a material balance in the solid phase, as shown below.

$$
\begin{aligned}
& -\frac{d\left(C_{\mathrm{A}} \cdot V\right)}{\mathrm{d} t}=\frac{d\left(C_{\mathrm{p}} \cdot V_{\mathrm{p}}\right)}{\mathrm{d} t} \\
& V_{\mathrm{p}}=\frac{\pi}{6} \dot{d}_{\mathrm{p}}^{3} \\
& C_{\mathrm{p}}=\frac{\rho_{s}}{M} \\
& -\frac{d\left(C_{\mathrm{A}} \cdot V\right)}{\mathrm{d} t}=C_{\mathrm{p}} \frac{\pi}{2} d_{\mathrm{p}}^{2} \frac{d}{\mathrm{~d} t}\left(d_{\mathrm{p}}\right)
\end{aligned}
$$

where $V_{\mathrm{p}}$ is the seed particle volume in $\mathrm{cm}^{3} ; d_{\mathrm{p}}$ is the average particle diameter in $\mathrm{cm} ; C_{\mathrm{p}}$ is the silica seed concentration in $\mathrm{mol} / \mathrm{L} ; \rho_{\mathrm{s}}$ is the silica seed density in $\mathrm{kg} / \mathrm{L}$; and $M$ is the molecular weight of silica seed, which was $60.08 \mathrm{~g} / \mathrm{mol}$. Hence, the value of the surface area in Eq. 6 could be substituted by the overall surface area of the seeds $\left(A_{\mathrm{o}}\right)$, and Eq. 2 was added into Eq. 7 to replace the concentration of silica in the liquid phase:

$$
\begin{aligned}
& V\left(k_{\mathrm{c}} \cdot A_{\mathrm{o}} \cdot\left(C_{\mathrm{A}}-C_{\mathrm{Ai}}\right)\right)=\frac{\rho_{s}}{2 \cdot M} A_{\mathrm{o}} \frac{d}{\mathrm{~d} t}\left(d_{\mathrm{p}}\right) \\
& \frac{d\left(d_{\mathrm{p}}\right)}{\mathrm{d} t}=2 \frac{M}{\rho_{s}} V\left(k_{\mathrm{c}} \cdot\left(C_{\mathrm{A}}-C_{\mathrm{Ai}}\right)\right)
\end{aligned}
$$

where $\frac{d\left(d_{\mathrm{p}}\right)}{\mathrm{d} t}$ is the particle growth rate.

The rate of precipitation of monomeric silica in geothermal brine is determined by the gap between its concentration in bulk and brine saturation. In this work, a pseudo-equilibrium concentration $\left(C_{\mathrm{Ai}}\right)$ was applied to verify the mass transfer coefficient with seed addition (Fleming and Crerar 1982). $C_{\mathrm{Ai}}$ is defined as the silica concentration in brine near the equilibrium concentration in which the polymerization rate significantly decreases. Peck (1979) defines the term $C_{\mathrm{Ai}}$ as the silicic acid solubility on the silica surface exaggerated with absorbed silicic acid chemically. Silica is rapidly absorbed by solid silica as more random solid silica is formed, at $6 \mathrm{ppm}$ for quartz and $115 \mathrm{ppm}$ for amorphous compounds at $25^{\circ} \mathrm{C}$. This previous work was conducted to check the relationship between the degree of chemisorbed on the silica surface and the variation of solubility. The coverage is being controlled at saturation condition when driving force existed, $C_{\mathrm{A}}>C_{\mathrm{Ai}}$. Furthermore, the value of CAi can be obtained 
Table 1 Chemical composition and parameters of geothermal brine from the geothermal well (Unit 3A-3B) at Dieng geothermal power plant

\begin{tabular}{ll}
\hline $\mathrm{Na}$ & $7120 \mathrm{ppm}$ \\
$\mathrm{K}$ & $2200 \mathrm{ppm}$ \\
$\mathrm{Ca}$ & $401 \mathrm{ppm}$ \\
$\mathrm{Mg}$ & $0.319 \mathrm{ppm}$ \\
$\mathrm{Li}$ & $39.3 \mathrm{ppm}$ \\
$\mathrm{Fe}$ & $0.115 \mathrm{ppm}$ \\
$\mathrm{B}$ & $305 \mathrm{ppm}$ \\
$\mathrm{Al}$ & $<0.05 \mathrm{ppm}$ \\
$\mathrm{As}$ & $30.60 \mathrm{ppm}$ \\
$\mathrm{Cl}$ & $13,600 \mathrm{ppm}$ \\
$\mathrm{F}$ & $2.12 \mathrm{ppm}$ \\
$\mathrm{SO}_{4}$ & $2.65 \mathrm{ppm}$ \\
$\mathrm{NH}_{3}$ & $34.10 \mathrm{ppm}$ \\
$\mathrm{SiO}_{2}$ & $418.36 \mathrm{ppm}$ \\
\hline $\mathrm{pH}^{2} 6.56$ Conductivity $=36,100 \mathrm{umho} / \mathrm{cm}$ &
\end{tabular}

from the experimental data and explained by Bohlmann et al. (1980), (Weres et al. 1981), per van't Hoff's equation.

As described previously that the value of $C_{\mathrm{Ai}}$ can be obtained from experimental work, this work also performed the same method to minimize the error of modeling calculation. The value of $C_{\mathrm{Ai}}$ of the research can be shown in Table 2 which was calculated from final concentration of the experiment results multiplied by 1.01 (near equilibrium monomeric silica concentration). We assumed that the final concentration is the equilibrium monomeric silica concentration. To decrease the value of an unknown variable, the value of $C_{\mathrm{Ai}}$ is important to be determined. Moreover, the unknown value of $C_{\mathrm{Ai}}$ in Eq. 2 would be multiplied by $k_{c}$ which could not give parameter range of $k_{c}$.

Equations 2 and 8 can be solved simultaneously using Matlab ${ }^{\circledR}$ software to yield a value for $k_{\mathrm{c}}$. Furthermore, the value of $k_{\mathrm{c}}$ can also be expressed in a dimensionless variable correlation as follows:

$$
\begin{aligned}
S h & =2+a(R e)^{\mathrm{b}}(S c)^{\mathrm{c}} \\
S h & =\frac{k_{\mathrm{c}} d_{\mathrm{p}}}{D_{\mathrm{AB}}} \\
R e & =\frac{\rho v d_{\mathrm{p}}}{\mu} \\
S c & =\frac{\bar{v}}{D_{\mathrm{AB}}}
\end{aligned}
$$

where $S h$ is the dimensionless Sherwood number; $R e$ is the dimensionless Reynold number; $S c$ is the dimensionless Schmidt number; $D_{\mathrm{AB}}$ is the diffusivity of $A$ in solvent $B$ in $\mathrm{cm}^{2} / \mathrm{s}, \rho$ is the fluid density in $\mathrm{g} / \mathrm{cm}^{3} ; \mu$ is the viscosity in $\mathrm{g} / \mathrm{cm} \mathrm{s} ; \nu$ is the agitation speed in $\mathrm{m} / \mathrm{s}$; and $\bar{v}$ is the kinematic viscosity in $\mathrm{cm}^{2} / \mathrm{s}$. If the value of $R e$ is more than 25 , the 2 in Eq. 9 becomes negligible compared to the others, as written in Eq. 13. 


$$
\begin{aligned}
& \frac{k_{\mathrm{c}} d_{\mathrm{p}}}{D_{\mathrm{AB}}}=a\left(\frac{\rho v d_{\mathrm{p}}}{\mu}\right)^{\mathrm{b}}\left(\frac{\bar{v}}{D_{\mathrm{AB}}}\right)^{\mathrm{c}} \\
& \ln \left(\frac{k_{\mathrm{c}} d_{\mathrm{p}}}{D_{\mathrm{AB}}}\right)=b \cdot \ln \left(\frac{\rho v d_{\mathrm{p}}}{\mu}\right)+\left(\frac{1}{3} \ln \left(\frac{\bar{v}}{D_{\mathrm{AB}}}\right)+\ln (a)\right) \\
& y=b \cdot x+A
\end{aligned}
$$

Since the seed particles are relatively small, they can move freely following the flow of the surrounding fluid. Therefore, the power of Schmidt number in Eq. 13 can be assumed to be $1 / 3$ (Fogler 1999). The value of $D_{\mathrm{AB}}$ can be calculated using Wilke-Chang's equation described by Fogler (1999).

\section{Results and discussion}

Temperature and $\mathrm{pH}$ are important factors which affect silica solubility in a solution. The solubility of silica depends on the type of silica formed, which is largely influenced by the acidity of the solution. For example, quartz has a solubility limit of $6 \mathrm{mg} / \mathrm{L}$ at $25^{\circ} \mathrm{C}$, but at $84{ }^{\circ} \mathrm{C}$ the solubility increases fourfold to $26 \mathrm{mg} / \mathrm{L}$. Amorphous silica is less sensitive to temperature changes; solubility is $115 \mathrm{mg} / \mathrm{L}$ at $25^{\circ} \mathrm{C}$ and increases to $370 \mathrm{mg} / \mathrm{L}$ at $100{ }^{\circ} \mathrm{C}$ (Dove et al. 2008). The solubility of silica has been so well studied that the solubility and dissociation constants are well known as a function of temperature. It is, therefore, possible to model solubility at a range of $\mathrm{pH}$ over a range of temperatures (Melchior and Bassett 1989). While increased temperature also increases the solubility affecting the kinetics of polymerization to a higher rate. This phenomenon leads at times to an apparent decrease in solubility over short periods (Sheikholeslami et al. 2002).

Our experimental results show that the addition of seeds in the solution will decrease the silica concentration as seen in Fig. 3 for all pH and temperature variations. Hypothetically, the silica from the liquid phase was shifted into the solid phase by the presence of seeds. Furthermore, as described in Eq. 6, the decrease of silica concentration would enlarge the seeds particle size. It is also proved by the conformity of concentration data and model fitting as seen in Fig. 3. The silica concentration in Fig. 3 tends to decrease sharply at the beginning $(0-1800 \mathrm{~s})$ and then become smooth afterward. The concentration difference on the film layer as described on Fick's law takes control in the mass transfer process with a constant mass transfer coefficient. Therefore, a larger difference in silica concentration at an early process would enhance the mass transfer from the liquid into the solid phase and become slower for longer precipitation time.

Table $2 C_{A i}$ at various $\mathrm{pH}$ and temperature values

\begin{tabular}{llll}
\hline $\mathbf{p H}$ & \multicolumn{2}{c}{$\boldsymbol{C}_{\mathbf{A i}} \times \mathbf{1 0 ^ { \mathbf { 3 } } \mathbf { ~ } \mathbf { m o l } / \mathbf { L }}$} & \\
\cline { 2 - 4 } & $\mathbf{2 5}{ }^{\circ} \mathbf{C}$ & $\mathbf{4 0}{ }^{\circ} \mathbf{C}$ & $\mathbf{8 0}{ }^{\circ} \mathbf{C}$ \\
\hline 7 & 2.995 & 2.977 & 4.359 \\
8 & 3.231 & 3.240 & 5.449 \\
9 & 3.614 & 4.275 & 5.746 \\
\hline
\end{tabular}



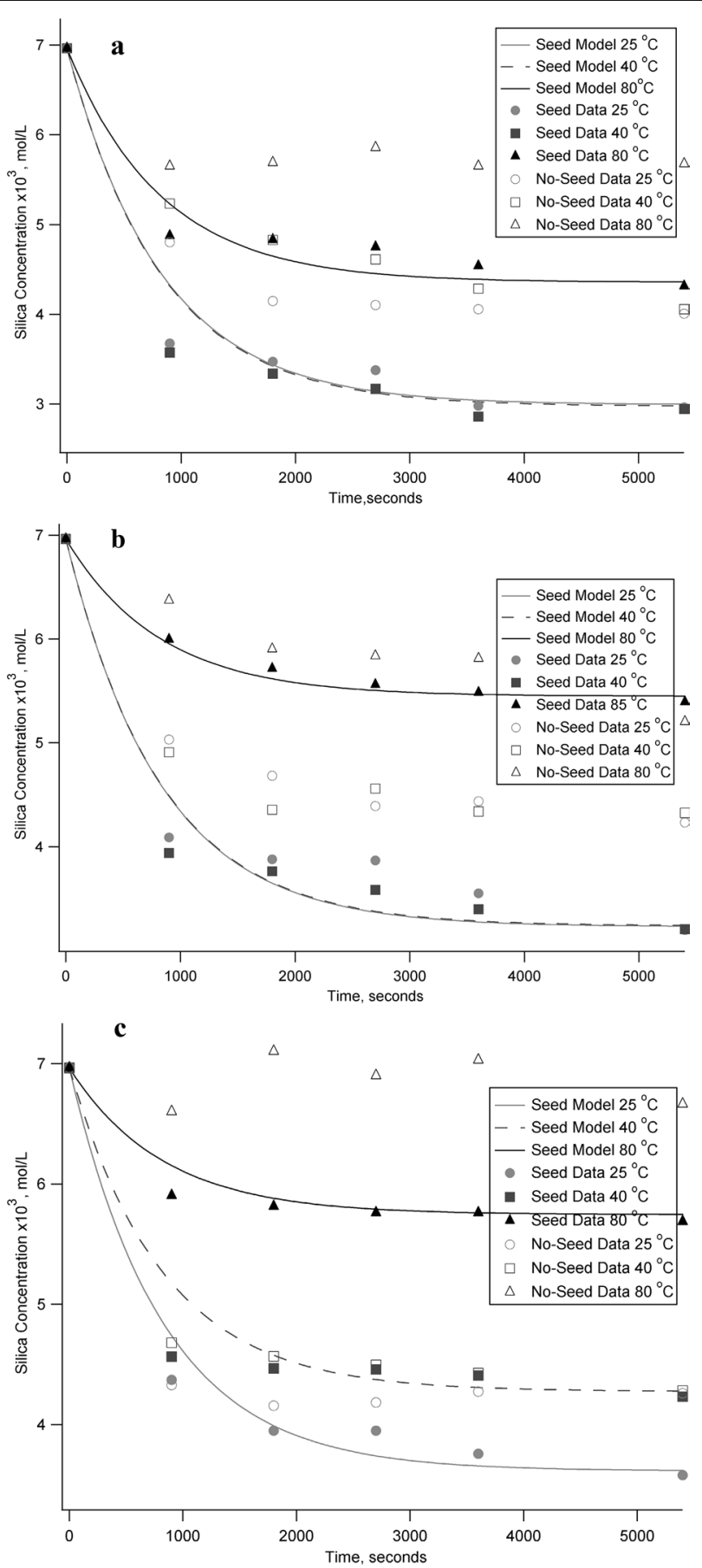

Fig. 3 Silica concentration data and model at various $\mathrm{pH}$ and temperatures; a pH 7 at various temperatures, b $\mathrm{pH} 8$ at various temperatures and $\mathbf{c} \mathrm{pH} 9$ at various temperatures

Compared to results from Sugita et al. (1998), the decreasing rate of monomeric silica by adding silica seed has the same tendency with the recent study. However further explanation on the phenomenon responsible for the decrease of silica concentration in the brine was not described in Sugita et al. (1998). Actually, Sugita et al. (2000) 
Table 3 Silica Saturation Index (SSI) with and without seed addition

\begin{tabular}{|c|c|c|c|c|c|c|}
\hline \multirow[t]{3}{*}{$\mathrm{pH}$} & \multicolumn{6}{|c|}{ Silica saturation index (SSI) } \\
\hline & \multicolumn{3}{|c|}{ With seed } & \multicolumn{3}{|c|}{ Without seed } \\
\hline & $25^{\circ} \mathrm{C}$ & $40^{\circ} \mathrm{C}$ & $80^{\circ} \mathrm{C}$ & $25^{\circ} \mathrm{C}$ & $40^{\circ} \mathrm{C}$ & $80^{\circ} \mathrm{C}$ \\
\hline 7 & 1.52 & 1.17 & 0.93 & 2.06 & 1.60 & 1.22 \\
\hline 8 & 1.64 & 1.26 & 1.14 & 2.18 & 1.70 & 1.22 \\
\hline 9 & 1.61 & 1.36 & 0.78 & 1.92 & 1.38 & 0.91 \\
\hline
\end{tabular}

had already proposed the kinetics of silica precipitation but could not give a clear explanation on the equation obtained. This study further explained the derivation of the formula and provided a solution for the implementation of calculated $k_{\mathrm{c}}$ value through dimensionless variable which can be used in scale-up process.

The silica saturation index (SSI) at Table 3 was used to compare processes with and without seed addition. Seed addition could eventually decrease the SSI on the precipitation process compared to that without seed addition. Although SSI values of seed addition are still above 1.2 in general, the value of SSI could be beneficial for deciding the further process parameter of silica mitigation. It seems that the higher the temperature and $\mathrm{pH}$, the less of the SSI value. The highest depreciation of SSI value is at the condition of $\mathrm{pH} 7$ and $40{ }^{\circ} \mathrm{C}$ temperature. This condition was further used to optimize the agitation speed and find the dimensionless variable correlation.

In addition, the $\mathrm{pH} 7$ and $40{ }^{\circ} \mathrm{C}$ temperature could be the optimum condition to mitigate silica scaling in geothermal plants before the cold re-injection system is conducted. The re-injection of geothermal brine usually occurs at the SSI value around 1.0-1.2 (Gallup and Hirtz 2010). The higher SSI value would not be recommended in the process of cold re-injection system. Meanwhile, one of the most common methods employed for mitigating silica deposits in geothermal brine-handling systems is hot brine injection at or near amorphous silica saturation (Henley 1983). The hot brine injection could be detrimental to the process of heat utilization from geothermal because hot brine still contains much energy. The cold re-injection system with silica mitigation is chosen because it can be used in the binary system to harvest the energy. Silica saturation index (SSI) was calculated from the final monomeric silica concentration in this work divided by the silica saturated concentration, $C_{\mathrm{AS}}$, derived from Eikenberg (1990) study.

Figure 4 shows that the decrease of monomeric silica concentration in brine is faster at higher stirring speeds, as higher turbulence in the fluid results in a lower mass transfer resistance for the precipitation of monomeric silica onto particle surfaces. This condition will eventually increase the mass transfer coefficient $\left(k_{\mathrm{c}}\right)$. The polymerization process appeared stable after $5400 \mathrm{~s}$, as shown by the similarities among final concentration data on various stirring velocities. The identical final concentration of monomer silica in Fig. 4 is caused by similar applied $\mathrm{pH}$ and temperature conditions. Specific $\mathrm{pH}$ and temperature affect the solubility of silica monomer in the solution.

Differences in geothermal well properties are a constraining factor in the utilization of geothermal energy. An appropriate method of analysis would allow the correlation of certain variables. This is urgently needed due to the complexity and differences in brine 


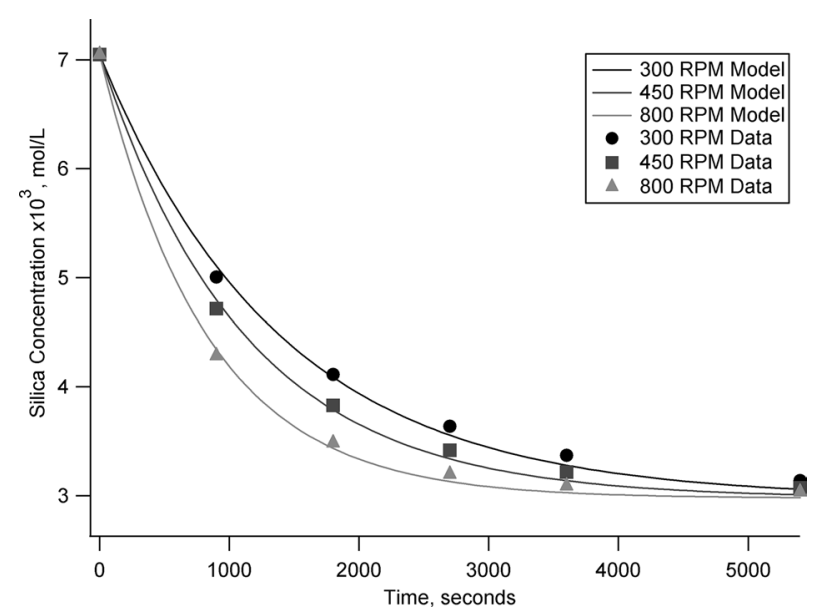

Fig. 4 Silica concentration data and model at various agitation speed at $\mathrm{pH} 7$ and $40{ }^{\circ} \mathrm{C}$

composition within a geothermal well. The addition of a dimensionless variable in this study permits the correlation of several variables used to describe the process. Agitation speed was varied to generalize the $k_{\mathrm{c}}$ value and analyze the dimensionless correlation in Eq. 13. The value of $k_{\mathrm{c}}$ at different stirring velocities is listed in Table 4. The range of $k_{\mathrm{c}}$ seems remarkable because of the $95 \%$ confidence interval obtained.

The $k_{\mathrm{c}}$ value can be used to evaluate the dimensionless correlation as stated in Eqs. 12 and 13. Calculation results using the dimensionless number are also presented in Table 5. The value of $D_{\mathrm{AB}}$ for the given polymerization conditions was found to be $4.1440 .10^{-5} \mathrm{~cm}^{2} / \mathrm{s}$. Agitation speed variation was conducted at $40{ }^{\circ} \mathrm{C}$ and $\mathrm{pH}$ 7. As seen in Table 4, the $k_{\mathrm{c}}$ value at $300 \mathrm{rpm}$ agitation is $0.3526 \mathrm{~cm} / \mathrm{s}$ which leads to a precipitation rate of $2.2 \mathrm{mg} /$ day. This value is slightly higher compared to that reported for silica precipitation on stainless steel surface pipe which was $1.96 \mathrm{mg} /$ day (van den Heuvel et al. 2018).

In Table 5, it appears that the Reynolds number is in the range of the transition regime (10-1000). This area is the appropriate region to evaluate the value of $k_{\mathrm{c}}$ because of the ideal mass transfer resistance. The mass transfer resistance would be

Table 4 Mass transfer coefficient as a function of agitation speed

\begin{tabular}{ll}
\hline Agitation speed(rpm) & $\mathbf{k c}(\mathbf{c m} / \mathbf{s})$ \\
\hline 300 & $0.3526 \pm 0.0049$ \\
450 & $0.4378 \pm 0.0073$ \\
800 & $0.5924 \pm 0.0142$ \\
\hline
\end{tabular}

Table 5 Calculations of the values of $\boldsymbol{a}$ and $\boldsymbol{b}$ in the dimensionless correlation

\begin{tabular}{llllll}
\hline $\begin{array}{l}\text { Agitation speed } \\
\text { (rpm) }\end{array}$ & Re & Sc & Sh & y=ln (Sh) & x=ln (Re) \\
\hline 300 & 256.25 & 185.77 & 152.6242 & 5.0280 & 5.5462 \\
450 & 384.35 & 185.7 & 189.5302 & 5.2445 & 5.9516 \\
800 & 683.3202 & 185.7688 & 256.4719 & 5.5470 & 6.5270 \\
\hline
\end{tabular}




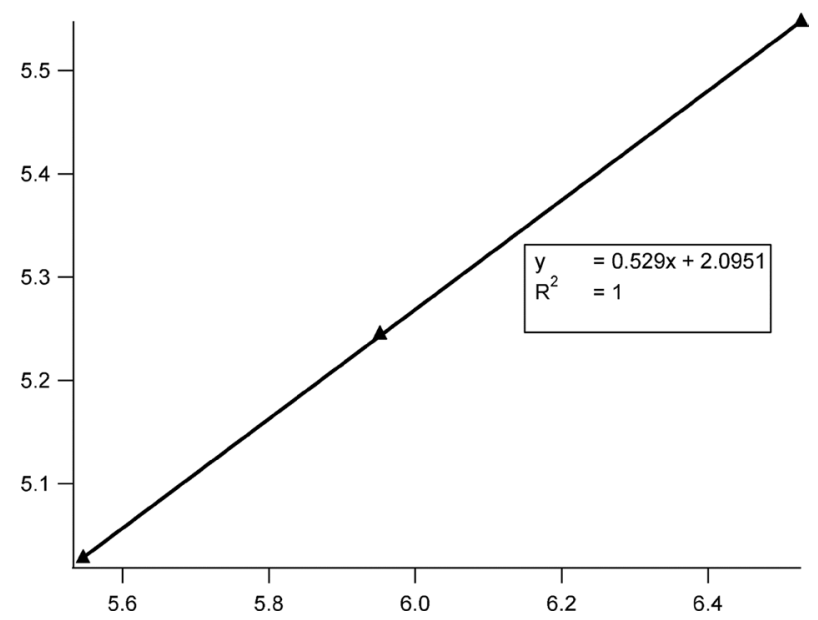

Fig. 5 Regression linear of dimensionless variable to calculate values for $a$ and $b$

too large in the laminar regime and too small at the turbulent regime. The system affects the film layer formed between the liquid and solid phase which controls the entire silica mitigation process. Figure 5 produces the linearization of equation which could be derived to calculate the value of $a$ and $b$ as in Eq. 15. The resulting dimensionless correlation from this work is expressed in Eq. 16.

$$
\frac{k_{\mathrm{c}} d_{\mathrm{p}}}{D_{\mathrm{AB}}}=1.2989 R e^{0.5507} S c^{0.3333}
$$

Equations 9 and 13 provide a correlation of $k_{\mathrm{c}}$ as $R e$ and $S c$ number functions. The value of $b$ in these equations (Eqs. 9 and 13) was around 0.53, which is suitable for small particles measuring 0.52 (Perry et al. 1997). Results show that effluent discharges are in the transition region, as shown in the Reynolds number in Table 5, confirming that the dimensionless correlation produced is valid for use in the transition zone (10-1000).

A morphology analysis using SEM was conducted to analyze the effects of the precipitation process on the seeds. Figure 6 shows the liquid phase silica attached to the solid phase as seen in the seed image taken after the precipitation process. Our results demonstrated that the precipitated mass was less than that estimated by Sugita et al. (2000). Precipitation of silica without seeds addition is also shown in Fig. 6c, showing that the silica formed had a smoother surface and lacked attached contaminants as compared to silica formed with seed addition.

From Fig. 6, we could not observe the dimension change during precipitation process either with or without seed addition. Thus, PSA analysis was conducted to show differences on silica precipitation with or without seed addition. Figure 7 and Table 6 clearly describe the difference between the two processes. It is clearly seen that diameter distribution of precipitated silica with seed addition has a narrow band. The diameter distribution without silica seed addition has a broader band and larger 


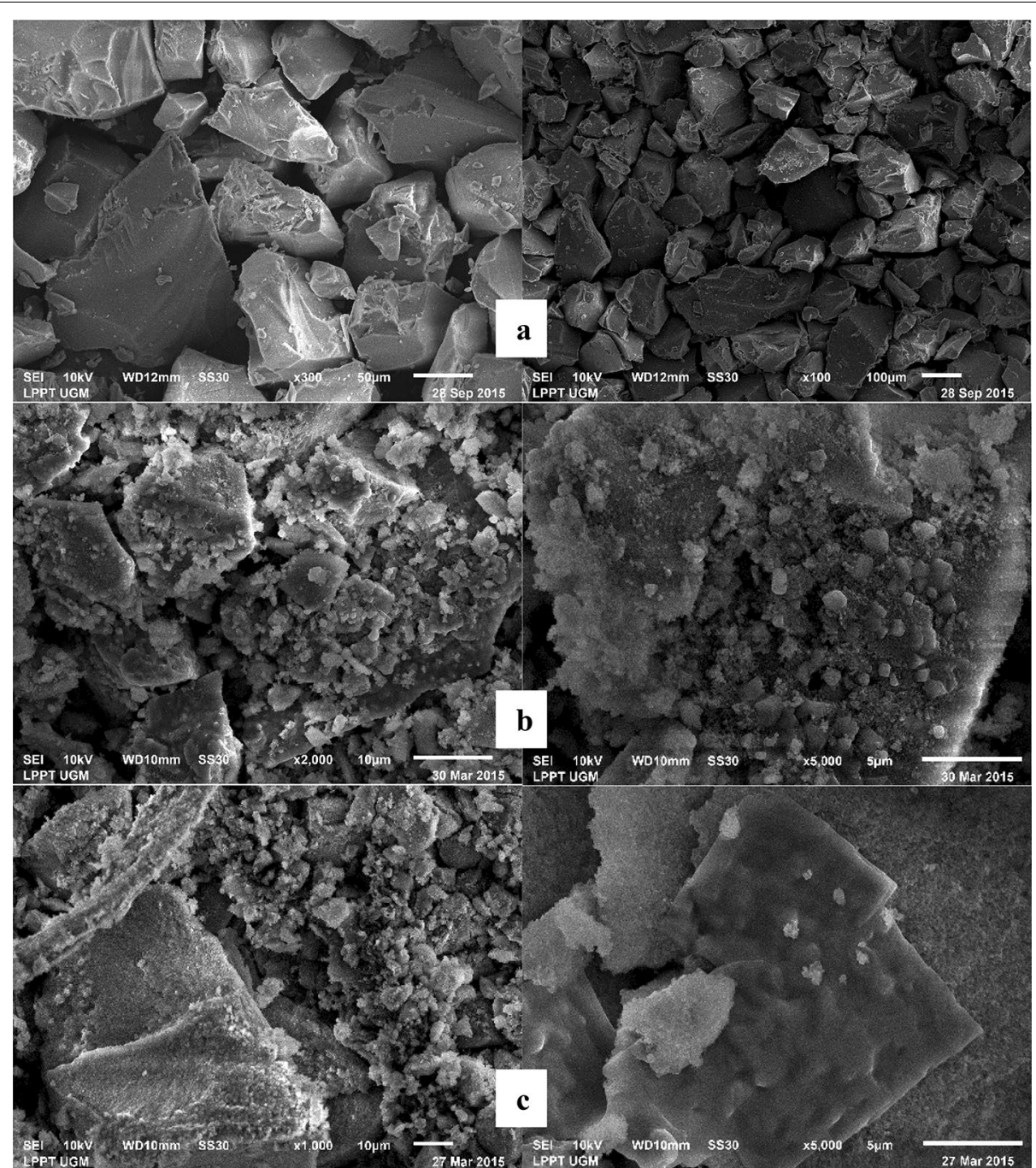

Fig. 6 SEM image of silica gel with various zoom: $\mathbf{a}$ initial seed and $\mathbf{b}$ after the precipitation process with adding seeds at $\mathrm{pH} 8$ and temperature $25^{\circ} \mathrm{C}, \mathbf{c}$ after the precipitation without adding seeds at pH 8 and temperature $25^{\circ} \mathrm{C}$, all process conducted at 800 rpm agitation rate

diameter which is undesirable for further silica mitigation process. The broader diameter distribution makes the equipment design become more complicated. Furthermore, the volume-based mean diameter from Table 6 shows that silica seed addition gives larger diameter compared to the process without silica seed addition. The addition of silica seeds eventually will contribute to the silica mitigation process.

To conclude, the addition of seeds shows promise for addressing high silica concentrations at geothermal power plants. A flow diagram process (FDP) (Fig. 8) is hereby proposed to mitigate silica scaling and was designed to optimize a sustainable process 


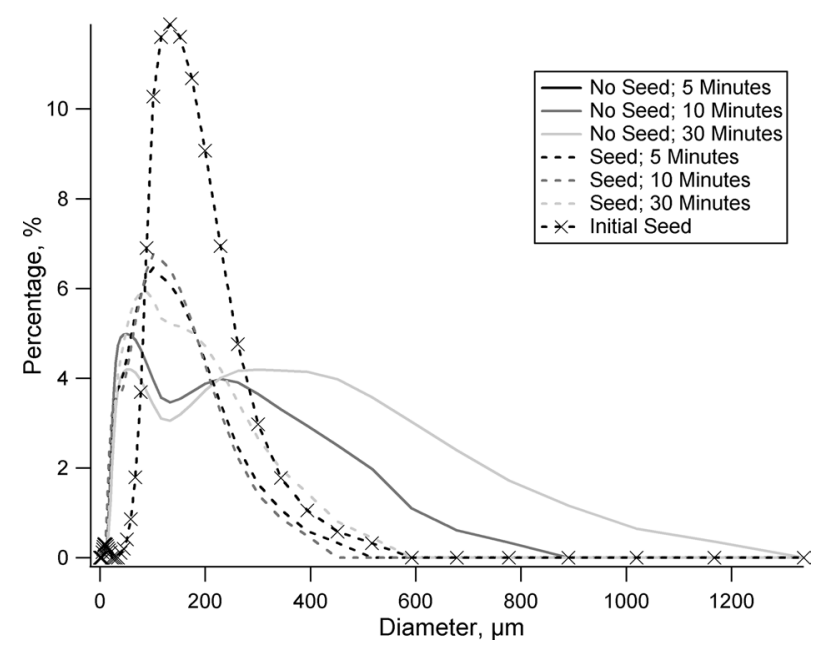

Fig. 7 Particle size analyzer results of silica mitigation process at $800 \mathrm{rpm}, \mathrm{pH} 8$ and $25^{\circ} \mathrm{C}$

Table 6 Volume-based mean diameter of silica precipitation process

\begin{tabular}{|c|c|c|c|c|c|}
\hline \multicolumn{3}{|c|}{ Without seed diameter (mm) } & \multicolumn{3}{|c|}{ With seed diameter (mm) } \\
\hline $5 \mathrm{~min}$ & $10 \mathrm{~min}$ & $30 \mathrm{~min}$ & $5 \mathrm{~min}$ & $10 \mathrm{~min}$ & $30 \mathrm{~min}$ \\
\hline 4.30 & 4.30 & 3.82 & 5.42 & 5.61 & 5.15 \\
\hline
\end{tabular}

at the geothermal power plant by implementing heat integration and silica mitigation. The heat integration in this proposed system uses working fluid, commonly an organic compound, to harvest and utilize more energy from the geothermal fluid. Silica mitigation produces more silica seeds and other silica-derived products. This method could render a more optimal and sustainable utilization of geothermal power. This approach would then emphasize the current trend to utilize energy from geothermal brine or condensate in a binary system while also resulting in an easier water re-injection (Skog 2019).

\section{Conclusion}

The addition of seeds significantly decreased the amount of silica in the liquid phase compared to no seed addition. Precipitation is dominated by mass transfer from the liquid phase into the solid phase, and our method was validated through the suitability of silica concentration data and model fit. We found that silica approached equilibrium concentration between 1200 and 1800 s. The higher the stirring velocity, the higher the mass transfer (also precipitation rate) coefficient. Temperature and $\mathrm{pH}$ also affect 


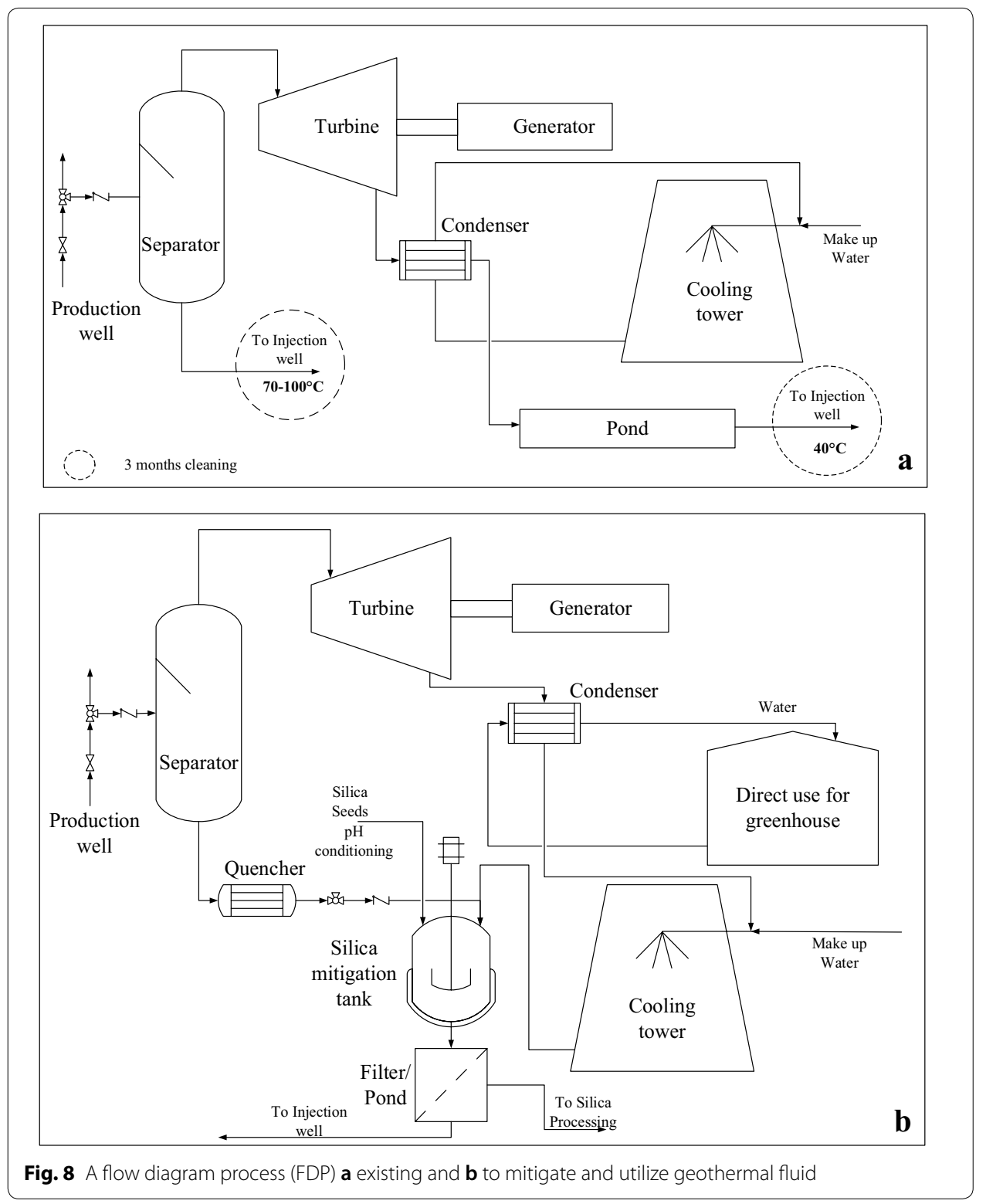

equilibrium concentration by influencing the force of the silica mass transfer process from liquid to solid phases. This research found the optimal parameters to be $\mathrm{pH} 7$, $40{ }^{\circ} \mathrm{C}$, and agitation speed of $800 \mathrm{rpm}$. The value of $k_{\mathrm{c}}$ can be derived from the dimensionless correlation equation shown below.

$$
\frac{k_{\mathrm{c}} d_{\mathrm{p}}}{D_{\mathrm{AB}}}=1.4242 R e^{0.529} S c^{0.3333}
$$




\section{Abbreviations}

$A$ : seed surface area with time, $\mathrm{cm}^{2} ; A_{0}$ : initial seed surface area, $\mathrm{Cm}^{2} ; C_{A}$ : silica concentration with time, $\mathrm{mol} / \mathrm{L} ; C_{\mathrm{Ai}}$ : preequilibrium silica concentration, mol/L; $C_{A s}$ : saturated concentration of monomer silica; $C_{\mathrm{p}}$ : silica seed concentration,

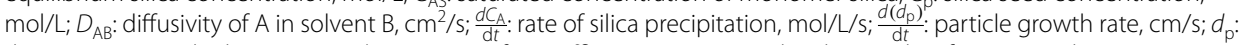
the average particle diameter, $\mathrm{cm} ; k_{c}$ : mass transfer coefficient, $\mathrm{cm} / \mathrm{s} ; \mathrm{M}$ : molecular weight of $\mathrm{SiO}_{2}, \mathrm{~g} / \mathrm{mol} ; \mu$ : viscosity, g/ $\mathrm{cm}-\mathrm{s}$; Re: Reynold number, dimensionless; $\rho$ : fluid density, $\mathrm{g} / \mathrm{cm}^{3} ; \rho_{s}$ : silica seed density, $\mathrm{kg} / \mathrm{L} ; \mathrm{Sc}$ : Schmidt number, dimensionless; Sh: Sherwood number, dimensionless; $V$ : total volume of solution, $L ; V_{\mathrm{p}}$ : seed particle volume, $\mathrm{cm}^{3} ; v$ : agitation speed, $\mathrm{cm} / \mathrm{s} ; \bar{V}$ : kinematic viscosity or $(\mu / \rho)$ in units of $\mathrm{cm}^{2} / \mathrm{s}$.

\section{Acknowledgements}

The authors send gratitude to the CaRED Programme which supports the research and projects implemented by Geothermal Research Center UGM in collaboration with New Zealand Government (Grant No. 03/NZ/Dit-KA/2014).

\section{Authors' contributions}

Laboratory work was conducted by FAS. Discussion on the manuscript was thoroughly evaluated. The manuscript was written through the contributions of all authors. All authors read and approved the final manuscript.

\section{Funding}

The funding was gained from the New Zealand Government with collaboration on CaRED Programme.

\section{Availability of data and materials}

All information and data necessary to understand the results and conclusions drawn in the paper are in the text, tables, and Figures or can be asked to the corresponding author.

\section{Competing interests}

The authors declare that they have no competing interests.

\section{Author details}

${ }^{1}$ Dept. of Chemical Engineering, Faculty of Engineering, University of Jember, Jl. Kalimantan No. 37 Kampus Tegal Boto, Sumbersari, Jember, Jawa Timur 68121, Indonesia. ${ }^{2}$ Dept. of Chemical Engineering, Faculty of Engineering, Universitas Gadjah Mada, Jl. Grafika 2 Bulaksumur, Yogyakarta 55281, Indonesia. ${ }^{3}$ Geothermal Research Centre, Universitas Gadjah Mada, Jl. Grafika 2 Bulaksumur, Yogyakarta 55281, Indonesia. ${ }^{4}$ PT. Geo Dipa Energi (Persero) Unit Dieng, J. Dieng RT. 01/ RW. 01, Area Industri, Sikunang, Banjarnegara, Kabupaten Wonosobo, Jawa Tengah 56354, Indonesia.

Received: 13 March 2019 Accepted: 29 July 2019

Published online: 20 August 2019

\section{References}

Bohlmann EG, Mesmer RE, Berlinski P. Kinetics of silica deposition from simulated geothermal brines. Soc Petrol Eng J. 1980;20(04):239-48. https://doi.org/10.2118/7889-PA.

Brown K. Thermodynamics and kinetics of silica scaling. In: Paper presented at the proceedings of international workshop on mineral scaling; 2011.

Dove PM, Han N, Wallace AF, De Yoreo JJ. Kinetics of amorphous silica dissolution and the paradox of the silica polymorphs. Proc Natl Acad Sci. 2008;105(29):9903-8. https://doi.org/10.1073/pnas.0803798105.

Durham B, Walton A. Membrane pretreatment of reverse osmosis: long-term experience on difficult waters. Desalination. 1999;122(2-3):157-70. https://doi.org/10.1016/S0011-9164(99)00037-5.

Eikenberg J. On the problem of silica solubility at high pH. Int Nucl Inf Syst. 1990;90:54

Fleming B, Crerar D. Silicic acid ionization and calculation of silica solubility at elevated temperature and pH application to geothermal fluid processing and reinjection. Geothermics. 1982;11(1):15-29. https://doi.org/10.1016/03756505(82)90004-9.

Fogler HS. Elements of chemical reaction engineering. New Delhi: Prentice Hall of India; 1999.

Gallup DL, Hirtz PN. Control of silica scaling in geothermal systems using silica inhibitors, chemical treatment, and process engineering. The Science and Technology of Industrial Water Treatment. Boca Raton: CRC Press; 2010. p. $160-82$.

Haklıdır FST, Balaban TÖ. A review of mineral precipitation and effective scale inhibition methods at geothermal power plants in West Anatolia (Turkey). Geothermics. 2019;80:103-18.

Haklidir FT, Haklidir M. Fuzzy control of calcium carbonate and silica scales in geothermal systems. Geothermics. 2017;70:230-8.

Henley RJG. pH and silica scaling control in geothermal field development. Geothermics. 1983;12(4):307-21. https://doi. org/10.1016/0375-6505(83)90004-4.

Jarvenin G. Precipitation and crystallization processes. Consortium for risk evaluation with stakeholder participation (CRESP); 2008, p. 16-8.

Kashpura V, Potapov V. Study of the amorphous silica scales formation at the Mutnovskoe hydrothermal field (Russia). In: Paper presented at the Proceedings of the 25th Stanford Workshop on Geothermal reservoir engineering, Stanford, USA; 2000.

Klein CW. Management of fluid injection in geothermal wells to avoid silica scaling at low levels of silica oversaturation. 1995. https://www.osti.gov/biblio/175671.

Melchior DC, Bassett RL. Chemical modeling of aqueous systems 2. United States: American Chemical Society; 1989.

Mersmann A. Crystallization technology handbook. Boca Raton: CRC Press; 2001. 
Milne NA, O'Reilly T, Sanciolo P, Ostarcevic E, Beighton M, Taylor K, Gray SR. Chemistry of silica scale mitigation for RO desalination with particular reference to remote operations. Water Res. 2014;65:107-33. https://doi.org/10.1016/j. watres.2014.07.010

Okamoto A, Saishu H, Hirano N, Tsuchiya N. Mineralogical and textural variation of silica minerals in hydrothermal flowthrough experiments: implications for quartz vein formation. Geochim Cosmochim Acta. 2010;74(13):3692-706. https://doi.org/10.1016/j.gca.2010.03.031.

Pambudi NA. Geothermal power generation in Indonesia, a country within the ring of fire: current status, future development and policy. Renew Sust Energy Rev. 2018;81:2893-901. https://doi.org/10.1016/j.rser.2017.06.096Get.

Pambudi NA, Itoi R, Yamashiro R, Alam BYCS, Tusara L, Jalilinasrabady S, Khasani J. The behavior of silica in geothermal brine from Dieng geothermal power plant, Indonesia. Geothermics. 2015;54:109-114. https://doi.org/10.1016/j. geothermics.2014.12.003

Peck LB. Polymerization of silica in aqueous solutions; 1979.

Perry RH, Green DW, Maloney JO. Perry's chemical engineers' handbook. New York: McGraw-Hill; 1997.

Petrus H, Hirajima T, Oosako Y, Nonaka M, Sasaki K, Ando T. Performance of dry-separation processes in the recovery of cenospheres from fly ash and their implementation in a recovery unit. Int J Miner Process. 2011;98(1-2):15-23. https ://doi.org/10.1016/j.minpro.2010.09.002.

Sheikholeslami R, Al-Mutaz I, Tan S, Tan S. Some aspects of silica polymerization and fouling and its pretreatment by sodium aluminate, lime and soda ash. Desalination. 2002;150(1):85-92. https://doi.org/10.1016/S0011 -9164(02)00932-3.

Skog G. Current status and future outlook of geothermal reinjection: a review of the ongoing debate; 2019 .

Sugita H, Bando Y, Nakamura M. Removal of silica from geothermal brine by seeding method using silica gel. J Chem Eng Jpn. 1998;31(1):150-2. https://doi.org/10.1252/jcej.31.150.

Sugita H, Matsunaga I, Yamaguchi T. Silica scale prevention method using seed made from geothermal brine. Paper presented at the World Geothermal Congress; 2000.

Sugita H, Matsunaga I, Yamaguchi T, Kato K, Ueda A. Silica removal performance of seed from geothermal fluids. Geothermics. 2003;32(2):171-85. https://doi.org/10.1016/S0375-6505(03)00013-0.

Tai C, Chien W, Hsu J. Induction period of $\mathrm{CaCO}_{3}$ interpreted by the Smoluchowski's coagulation theory. AIChE J. 2005;51(2):480-6. https://doi.org/10.1002/aic.10304.

van den Heuvel DB, Gunnlaugsson E, Gunnarsson I, Stawski TM, Peacock CL, Benning LG. Understanding amorphous silica scaling under well-constrained conditions inside geothermal pipelines. Geothermics. 2018;76:231-41.

Weres O, Yee A, Tsao L. Kinetics of silica polymerization. J Colloid Interface Sci. 1981;84(2):379-402. https://doi. org/10.1016/0021-9797(81)90230-7.

Zlokarnik M. Scale-up in chemical engineering. New York: Wiley; 2006.

\section{Publisher's Note}

Springer Nature remains neutral with regard to jurisdictional claims in published maps and institutional affiliations.

\section{Submit your manuscript to a SpringerOpen ${ }^{\odot}$ journal and benefit from:}

- Convenient online submission

- Rigorous peer review

- Open access: articles freely available online

- High visibility within the field

Retaining the copyright to your article

Submit your next manuscript at $\gg$ springeropen.com 